\title{
Bioconjugate Chemistry
}

\section{Molecular Characterization of Multivalent Bioconjugates by Size- Exclusion Chromatography with Multiangle Laser Light Scattering}

\author{
Jacob F. Pollock, ${ }^{\dagger, \|}$ Randolph S. Ashton, ${ }^{\S}$ Nikhil A. Rode, ${ }^{\ddagger}$ David V. Schaffer, ${ }^{\S, \|}$ and Kevin E. Healy ${ }^{*}, \dagger, \downarrow$ \\ ${ }^{\dagger}$ Department of Bioengineering, ${ }^{\ddagger}$ Department of Materials Science and Engineering, ${ }^{\S}$ Department of Chemical Engineering, and \\ "UCSF/UCB Joint Graduate Group in Bioengineering, University of California at Berkeley, Berkeley, California, United States
}

\begin{abstract}
The degree of substitution and valency of bioconjugate reaction products are often poorly judged or require multiple time- and product-consuming chemical characterization methods. These aspects become critical when analyzing and optimizing the potency of costly polyvalent bioactive conjugates. In this study, size-exclusion chromatography with multiangle laser light scattering was paired with refractive index detection and ultraviolet spectroscopy (SEC-MALS-RI-UV) to characterize the reaction efficiency, degree of substitution, and valency of the products of conjugation of either peptides or proteins to a biopolymer scaffold, i.e., hyaluronic acid (HyA). Molecular characterization was more complete compared to estimates from a protein quantification assay, and exploitation of this method led to more accurate deduction of the molecular structures of polymer bioconjugates. Information obtained using this technique can improve macromolecular engineering design principles and help to better understand multivalent macromolecular interactions in biological systems.
\end{abstract}

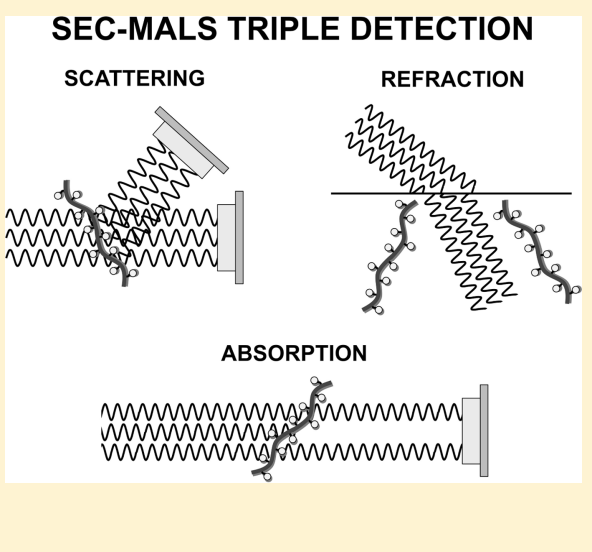

\section{INTRODUCTION}

Bioconjugation reaction methods have become increasingly important in biomaterial, biochemistry, pharmaceutical, and medical endeavors. They have been employed in diverse research fields for material synthesis, ${ }^{1}$ macromolecular engineering, ${ }^{2}$ biochemical modification, ${ }^{3,4}$ and surface treatment. ${ }^{5,6}$ A theme widely explored, for various medical applications, is the conjugation of a therapeutic biomolecule to either a synthetic or natural polymer or protein "scaffold" to create a decorated "carrier" for the bioactive agent. Knowing the true reaction efficiency, degree of substitution on the scaffold (i.e., the average number of ligands per potential reaction site on the molecular scaffold), conjugate valency (i.e., the average number of ligands per scaffold molecule), and macromolecule structure and size are crucial to understanding and controlling the chemical and biological performance of the conjugated scaffold.

Many extracellular proteins of mammalian tissue are multivalent and multifunctional, and this biochemical information directs cell behavior and tissue dynamics through receptor-ligand engagement and downstream signaling. ${ }^{7,8}$ Therefore, multivalent bioactive conjugates have the potential to greatly improve pharmaceutical and biomaterial potency, and reduce the need for inefficient and potentially harmful doses of expensive therapeutics. They may also alter receptor-ligand dynamics (e.g., increased ligand localization and avidity, inhibited complex internalization and degradation), which could lead to improved potency of peptide and protein conjugates. ${ }^{6,9}$ Furthermore, multivalent ligands have been known to increase activation of intracellular signaling when membrane-bound protein complexes are formed, ${ }^{10,11}$ and natural physiological roles of soluble extracellular signaling aggregates have been recognized. ${ }^{12}$ However, in many applications of bioconjugate reactions, the products are incompletely characterized in terms of molecular weight, degree of substitution, conjugate valency, and conjugate structure.

Conjugate valency is often poorly judged using common characterization techniques and can easily deviate from the expected. For example, for fixed weight concentrations of monomer and scaffold, the valency of a conjugate can vary considerably depending on the molecular weight of the scaffold. In addition, it is difficult to obtain information not only about the average valency, but the distribution of valencies within a preparation. Degradation, particularly of naturally derived or degradable polymer backbones (e.g., hyaluronic acid), can occur under the chemical conditions necessary for conjugation. Characterization of degrees of substitution and molecular weights therefore become critical when measuring the potency of various scaffolds, as well as in optimizing these multivalent biomimetic polymers for specific applications. ${ }^{2,13}$

Many chemical characterization techniques provide an incomplete picture of bioconjugate molecular structure, and therefore several are often used in conjunction. ${ }^{14}$ Mass spectrometry is highly sensitive, but requires the ability to deconvolute molecular fragments and is more appropriate for lower molecular weight derivatized proteins and conjugates. ${ }^{15-17}$ Protein quantification methods (e.g., bicinchoninic acid assay, Coomassie staining, ultraviolet light absorbance) can be used to estimate the average mass fraction of peptide or protein; ${ }^{2}$ however, in the absence of accompanying measure-

Received: February 7, 2012

Revised: June 26, 2012

Published: July 16, 2012 


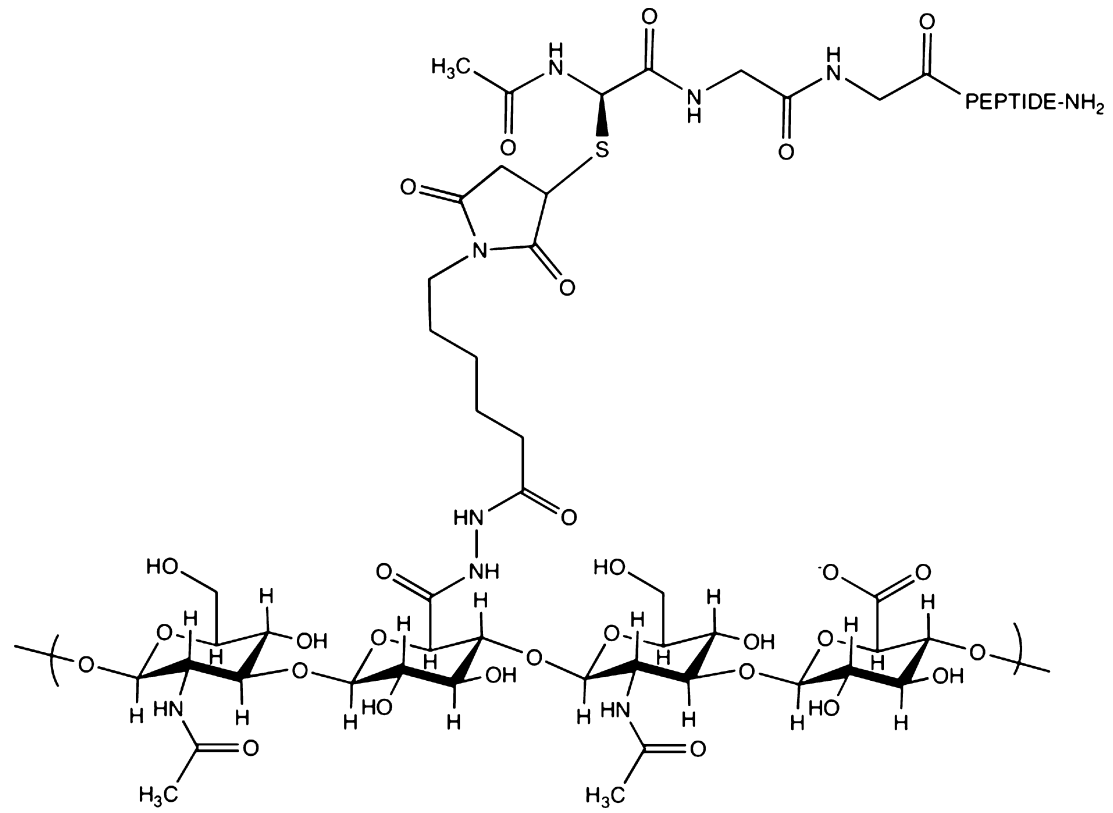

Figure 1. Hyaluronic acid-peptide conjugate chemical structure. A heterobifunctional linker was used to anchor peptide and protein via their terminal thiol-functional cysteine residues to the carboxylic acid groups of the linear hyaluronic acid polymer.

ments of scaffold concentration and molecular weight, these measurements do not provide direct information on the average or the distribution of conjugate valencies. Also, they generally require highly accurate protein standards that are difficult and time-consuming to prepare and validate. Fourier transform infrared spectroscopy (FTIR), ${ }^{18} \mathrm{UV}$-vis spectroscopy, ${ }^{19}$ and nuclear magnetic resonance $(\mathrm{NMR})^{20}$ provide molecular composition information, but end group identification or tagging is required for molecular weight characterization. These methods, along with biochemical, molecular biology, and fluorescence ${ }^{18}$ assays, provide only an average ligand content or total molecular weight with no indication of their distribution. While traditional chromatographic methods can be used to obtain relative physicochemical properties and chemical composition, ${ }^{16,17}$ light scattering methods can provide absolute molecular weight measurements without the use of standards. $^{21}$

In this work, we sought to develop a technique and workflow that would characterize the distributions of molecular masses and ligand valencies of an entire macromolecule population within a conjugate reaction product, using a single measurement system with a reasonable sample size $(<1.5 \mathrm{mg})$. An online three-detector method was used with continuous monitoring of differential refractive index (RI), ultraviolet light absorbance (UV), and multiangle laser light scattering (MALS) after size-exclusion chromatography (SEC). ${ }^{22,23}$ We explored the natural biopolymer hyaluronic acid as a model scaffold, since it has been studied for numerous medical and pharmaceutical applications. ${ }^{2,24-28}$ The reaction products of either peptides or proteins conjugated to a hyaluronic acid backbone were analyzed using this technique. The mass fractions and molecular weights determined were used to calculate valencies for comparison to those estimated using a standard protein quantification assay. We observed that reaction efficiency varied with the type and concentration of ligand conjugated. Furthermore, under some conditions the scaffold molecular weight decreased due to fragmentation of the backbone during the bioconjugation reaction. The triple detection method additionally provided novel information about ligand valency during this molecular weight change.

\section{MATERIALS AND METHODS}

Hyaluronic acid sodium salts (HyA) of 0.5 and 1.0 MDa MW served as the scaffolds for the conjugation reactions (Genzyme, Cambridge, MA). Conjugation reagents, including 1-ethyl-3-(3dimethylaminopropyl) carbodiimide hydrochloride (EDC), $N$ hydroxysulfosuccinimide (sulfoNHS), and [N-E-maleimidocaproic acid] hydrazide trifluoroacetic acid $(\mathrm{EMCH})$, were purchased from Thermo Scientific Pierce. Tris(2-carboxyethyl) phosphine (TCEP), Dulbecco's phosphate buffered saline (DPBS), 2-( $N$-morpholino)ethanesulfonic acid (MES), and $10 \mathrm{kDa}$ MW cutoff dialysis tubing (SnakeSkin) were also obtained from Pierce. All dry buffers were constituted in ultrapure ASTM type I reagent grade water $(<18.2 \mathrm{M} \Omega \cdot \mathrm{cm}$, pyrogen free, UPW). An Arg-Gly-Asp (RGD)-containing 15mer peptide derived from bone sialoprotein (AcCGGNGEPRGDTYRAY-NH ${ }_{2}$ : bsp-RGD(15) $)^{29}$ was synthesized (American Peptide Co., Sunnyvale, CA) with two glycine spacer amino acids and an acylated cysteine amino-terminus for coupling via thiol reaction with maleimide groups of an activated HyA backbone. Recombinant modified Sonic hedgehog (Shh) protein was produced as described below. All reactions were performed under aseptic conditions using sterile-filtered solutions and autoclaved containers and instruments.

Coupling of Peptide to Hyaluronic Acid. Hyaluronic acid was first activated with maleimide groups by carbodiimide coupling of EMCH. Hyaluronic acid sodium salt $0.5 \mathrm{MDa}$ (50 $\mathrm{mg}$ ) was added to $8 \mathrm{~mL}$ of MES buffer $(0.1 \mathrm{M}, \mathrm{pH} 6.5)$ and stirred under low shear until dissolved. Conjugation reagents (110 mg EDC, $30.8 \mathrm{mg}$ sulfoNHS, and $13.2 \mathrm{mg} \mathrm{EMCH}$ ) were dissolved in $2.2 \mathrm{~mL}$ MES buffer. Two $\mathrm{mL}$ of the conjugation reaction mixture was added through sterile-filter to the HyA solution and stirred. The final concentrations of each reagent for EMCH activation of HyA were as follows: $5 \mathrm{mg} / \mathrm{mL} \mathrm{HyA}$, $10 \mathrm{mg} / \mathrm{mL}$ EDC, $2.8 \mathrm{mg} / \mathrm{mL}$ sulfoNHS, and $1.2 \mathrm{mg} / \mathrm{mL}$ 
EMCH. The reaction was allowed to proceed for $2 \mathrm{~h}$ with stirring at room temperature in the dark. The solution was then thoroughly dialyzed through a $10 \mathrm{kDa}$ MWCO membrane against MES buffer (0.1 M, pH 6.5) and transferred to another reaction vessel.

The peptide was then reduced and added to the activated HyA-EMCH solution for conjugation via reaction of the maleimide moieties with the thiol group of the peptide. In order to reduce any potential disulfide bonds formed by the peptide via spontaneous oxidation, $3 \mathrm{mg}$ of $\mathrm{NaOH}$ and $5.7 \mathrm{mg}$ of TCEP were added to $1 \mathrm{~mL}$ UPW. The bsp-RGD peptide $(4.4 \mathrm{mg})$ was added to the alkaline reducing solution, allowed to react for $30 \mathrm{~min}$ at $4{ }^{\circ} \mathrm{C}$, and added through a sterile-filter to the activated $\mathrm{HyA}-\mathrm{EMCH}$ solution. The final solution was reacted overnight at $4{ }^{\circ} \mathrm{C}$ in the dark. The conjugate solution was then dialyzed three times for $2 \mathrm{~h}$ through a $10 \mathrm{kDa}$ MWCO membrane against UPW. After dialysis, the solution was transferred to a $50 \mathrm{~mL}$ Steriflip tube (BD Bioscience) and lyophilized through the sterile-filter cap. The dry product was stored at $-20{ }^{\circ} \mathrm{C}$ until characterization. The final chemical structure of the bioconjugate is depicted in Figure 1.

Recombinant Production of Modified Sonic Hedgehog Protein. A recombinant cysteine-modified N-terminal Shh was produced as previously described. ${ }^{2,31}$ A sequence encoding a cysteine residue and a $6 \mathrm{xHis}$ tag were added via PCR to $3^{\prime}$ end of cDNA encoding the N-terminal signaling domain of rat Shh to allow for sulfhydryl-based reactions and protein purification, respectively. The conjugation site was chosen because it is distant from the active receptor-binding domain. In addition, valine and isoleucine residues were introduced to the $\mathrm{N}$-terminus to increase potency by mimicking the hydrophobic palmitic acid modification of endogenous Shh. The modified Shh PCR product was inserted into a $\mathrm{pBAD}$ HisA plasmid (Invitrogen), sequenced for confirmation, and expressed in BL21(DE3)pLysE E. coli upon arabinose induction. The cells were lysed, and the resulting expressed Shh was purified using NiNTA binding through the BioRad DuoFlow System and elution with imidazole. The isolated protein was dialyzed into $\mathrm{pH} 7.4 \mathrm{PBS}$ containing $10 \%$ glycerol, $2 \mathrm{mM}$ EDTA, and $50 \mu \mathrm{M} \mathrm{ZnSO}_{4}$ and stored at $-20{ }^{\circ} \mathrm{C}$ until conjugation.

Conjugation of Sonic Hedgehog Protein to Hyaluronic Acid. The modified Shh protein was conjugated to 1.0 MDa HyA through a similar two-step reaction process to the bsp-RGD (HyA-bsp-RGD(15)), using carbodiimide chemistry at the carboxylate group of the HyA and maleimide reaction at the protein C-terminal cysteine. ${ }^{2}$ Hyaluronic acid was activated at $3 \mathrm{mg} / \mathrm{mL}$ in MES (0.1 M pH 5.0) with $3.9 \mathrm{mg} / \mathrm{mL}$ EDC, 1.1 $\mathrm{mg} / \mathrm{mL}$ sulfoNHS, and $0.5 \mathrm{mg} / \mathrm{mL}$ EMCH. Activated HyA was purified by sequential dilution and centrifugation in $100 \mathrm{kDa}$ MWCO centrifuge filters (Pall Gellman). The activated HyA$\mathrm{EMCH}$ was reacted with the modified Shh at varying stoichiometric feed ratios to produce conjugates with different conjugate valency. The reaction was performed at $4{ }^{\circ} \mathrm{C}$ overnight in MES buffer (0.1 M pH 6.5) with $50 \mu \mathrm{M}$ TCEP to maintain cysteine reduction. Following the reaction, the remaining maleimide groups were quenched by the addition of $0.5 \mathrm{mM}$ dithiothreitol and incubation at $4{ }^{\circ} \mathrm{C}$ for $1 \mathrm{~h}$. The HyA-Shh conjugation product was dialyzed into $\mathrm{pH} 7.4$ PBS containing $2 \mathrm{mM}$ EDTA and $50 \mu \mathrm{M} \mathrm{ZnSO} 4$ and stored at -20 ${ }^{\circ} \mathrm{C}$ until characterization.

SEC-MALS-RI-UV Analysis of Bioconjugates. The SECMALS-RI-UV setup consisted of an Agilent HPLC 1100 (including degasser, quaternary pump, autosampler, column holder, and UV-vis diode array detector) in line with a DAWN-EOS multiangle laser light scattering detector and Optilab-DSP relative refractive interferometer (Wyatt Technology, Santa Barbara, CA). Refractive index change was measured differentially with a GaAs laser at a wavelength of 690 $\mathrm{nm}$, and UV absorbance was measured with the diode array detector at $280 \mathrm{~nm}$. A PolySep-GFC-P Linear column was used for the HPLC (Phenomenex). HyA-peptide and HyA-protein conjugates were injected at $5 \mathrm{mg} / \mathrm{mL}$ and $3 \mathrm{mg} / \mathrm{mL}$ conjugate, respectively. The temperatures of the DSP and column holder were both maintained at $45{ }^{\circ} \mathrm{C}$. Agilent software was used to control the HPLC, and Wyatt Astra $V$ software was used for data collection and analysis. Normalization of the multiangle detectors was performed with $300 \mu \mathrm{L}$ of $5 \mathrm{mg} / \mathrm{mL}$ bovine serum albumin (BSA) (Aldrich) in DPBS at a flow rate of 0.8 $\mathrm{mL} / \mathrm{min}$ (used throughout unless otherwise noted) with DPBS as the mobile phase. Peak alignment and band broadening correction between the UV, MALS, and RI detectors were performed using Astra software algorithms. Analysis was restricted to detectors at moderate angles due to high noise at very low and very high angle detectors.

The specific refractive index values of the peptide, protein, $\mathrm{HyA}$, and HyA-EMCH were confirmed by a $100 \%$ mass recovery method at a wavelength of $690 \mathrm{~nm}$ (the same as used in online detection). The UV absorbance coefficient values for each conjugate component were measured using an off-line $\mathrm{UV}$-vis spectrophotometer at $280 \mathrm{~nm}$ wavelength. These values were confirmed using a $100 \%$ mass recovery method to corroborate UV and RI concentration source detectors. Zimm plots were created for $0.5 \mathrm{MDa}$ HyA scaffold and a conjugate of $0.5 \mathrm{MDa} H y A$ with bsp-RGD(15) at a 1 to 25 molar ratio (1:25, HyA:bsp-RGD(15)) using $200 \mu \mathrm{L}$ injections of 1, 2, 3, and $4 \mathrm{mg} / \mathrm{mL}$ in DPBS at $45{ }^{\circ} \mathrm{C}$ with DPBS as the mobile phase.

\section{RESULTS AND DISCUSSION}

Online SEC-MALS-RI-UV Analysis of Hyaluronic Acid Bioconjugates. Measurement of RI, UV, and MALS signals allowed simultaneous online measurement of concentration, conjugate molar mass, and ligand mass fraction distribution among the modified polymer chains. Table 1 lists the physicochemical parameters of the conjugate components employed in this study. The weight-averaged molar mass $\left(M_{w}\right)$ and $z$-averaged radius of gyration $\left(R_{G, z}\right)$ were determined for each slice along the chromatogram (Figure $2 \mathrm{a}$ ) using the Rayleigh-Gans-Debye equation

Table 1. Specific Refractive Indices $(\partial n / \partial c)$ and $280 \mathrm{~nm}$ Absorbance Coefficients $\left(\varepsilon_{\text {abs }}\right)$ for Hyaluronic Acid, EMCHActivated Hyaluronic Acid, Peptide, and Proteins

\begin{tabular}{|c|c|c|c|c|}
\hline component & $\begin{array}{c}\partial n / \partial c \\
(\mathrm{~mL} / \mathrm{g})\end{array}$ & $\begin{array}{c}\varepsilon_{\mathrm{abs}} \\
(\mathrm{mL} / \mathrm{g} \mathrm{cm})\end{array}$ & $\mathrm{MW}_{\mathrm{w}}$ & sequence \\
\hline HyA & 0.167 & 22 & $\begin{array}{l}0.5 \text { and } \\
1.0 \\
\mathrm{MDa}\end{array}$ & \\
\hline $\begin{array}{l}\text { HyA- } \\
\text { EMCH }\end{array}$ & 0.167 & 22 & & \\
\hline bspRGD & 0.185 & 1840 & 1657 & $\begin{array}{l}\text { Ac- } \\
\text { CGGNGEPRGDTYRAY- } \\
\text { NH2 }\end{array}$ \\
\hline Shh & 0.185 & 974 & 21376 & $\begin{array}{l}\text { See reference (Wall et al. } \\
\text { Bioconjugate Chem, 2008) }\end{array}$ \\
\hline
\end{tabular}



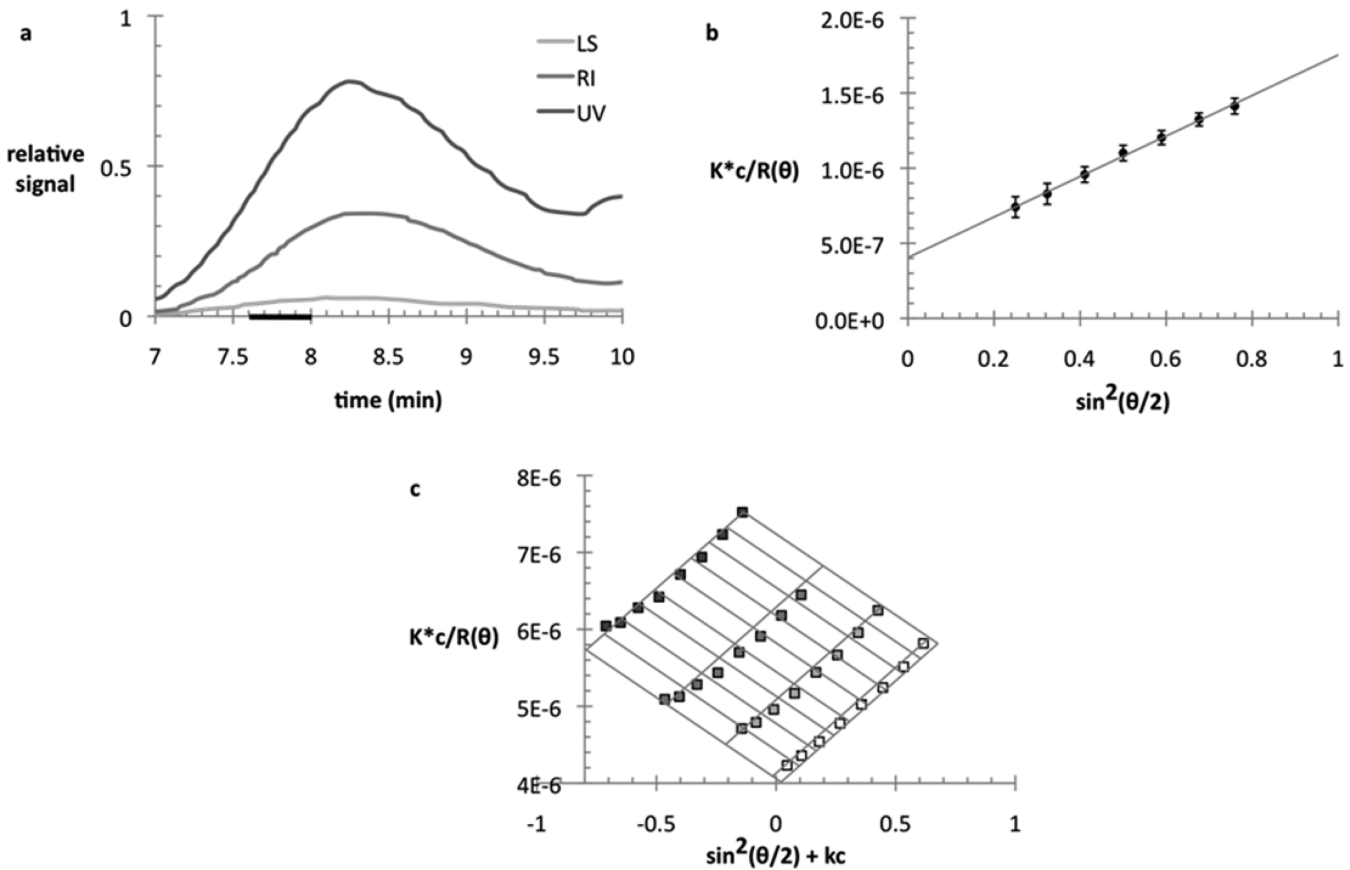

Figure 2. Representative chromatogram (a) with $90^{\circ}$ light scattering (LS), refractive index (RI), and ultraviolet light absorbance (UV) signals and Debye plot (b) calculated from multi-angle laser light scattering (MALS) data at slices along the size-exclusion chromatogram for HyA-bspRGD(15) (1:25, HyA:bsp-RGD(15) molar reaction ratio). A Zimm plot (c) created from injectons of varying total conjugate mass for HyA-bsp$\operatorname{RGD}(15)$ (1:25) used to calculate weight-averaged molecular mass $\left(M_{\mathrm{w}}\right), z$-averaged radius of gyration, $\left(R_{G, z z}\right)$ and second virial coefficient $\left(A_{2}\right)$.

$$
\begin{aligned}
\frac{K^{*} c}{R(\theta)} & =\frac{1}{P(\theta)}\left(\frac{1}{M_{\mathrm{w}}}+2 A_{2} c+3 A_{3} c^{2}+\ldots\right) \\
K^{*} & =\frac{4 \pi^{2} n_{0}^{2}\left(\frac{\partial n}{\partial c}\right)^{2}}{N_{\mathrm{A}} \lambda_{0}^{4}} \\
\frac{1}{P(\theta)} & =1+\frac{16 \pi^{2}}{3 \lambda^{2}} R_{G, z}^{2} \sin ^{2}\left(\frac{\theta}{2}\right)+\ldots
\end{aligned}
$$

where $c$ is the concentration of polymer in solution, $R(\theta)$ is the excess Rayleigh scattering ratio, $A_{2}$ is the second virial coefficient, $A_{3}$ is the third virial coefficient, $\theta$ is the scattering angle, and $(\partial n) /(\partial c)$ is the specific refractive index increment of the macromolecule in solution. Debye plots $\left(K^{*} c / R(\theta)\right.$ vs $\left.\sin ^{2}(\theta / 2)\right)$ were created for each slice along the chromatogram (Figure $2 \mathrm{~b})$. Zimm plots $\left(K^{*} c / R(\theta)\right.$ vs $\left.\sin ^{2}(\theta / 2)+k c\right)$ were also constructed by injecting a series of concentrations through the SEC-MALS system, which gave the $A_{2}, R_{G, z}$, and $M_{\mathrm{w}}$ values of the backbone polymer and a representative conjugate (Figure 2c and Table 2).

The use of two concentration detectors (RI and UV) in combination with SEC-MALS allowed characterization of the molecular weight distribution and the relative composition of

Table 2. Weight-Averaged Molecular Mass $\left(M_{\mathrm{w}}\right)$, $z$-Averaged Radius of Gyration $\left(R_{G, z}\right)$, and Second Virial Coefficient $\left(A_{2}\right)$ for HyA and HyA-bsp-RGD(15) (1:25) as Determined by Zimm Plot Construction (as Measured at $45^{\circ} \mathrm{C}$ in Phosphate Buffer)

\begin{tabular}{lclc}
\multicolumn{1}{c}{ sample } & $\begin{array}{c}\mathrm{MW}_{\mathrm{w}}\left(10^{5} \mathrm{~g} /\right. \\
\mathrm{mol})\end{array}$ & $R_{\mathrm{G}, z}(\mathrm{~nm})$ & $\begin{array}{c}\mathrm{A}_{2}\left(10^{-3}\right. \\
\left.\mathrm{mol} \mathrm{mL} / \mathrm{g}^{2}\right)\end{array}$ \\
\hline HyA, 0.5 MDa & $4.9 \pm 0.24$ & $55 \pm 3.5$ & $2.4 \pm 0.76$ \\
HyA-RGD (1:25) & $2.1 \pm 0.74$ & $70 \pm 15.8$ & $3 \pm 1.6$
\end{tabular}

conjugated macromolecules. This was possible since the measured values of specific refractive index $(\partial n / \partial c)$ and UV absorption coefficient $\left(\varepsilon_{\text {abs }}\right)$ along the chromatogram are weight-averaged values for each component individually

$$
\begin{gathered}
\left(\frac{\partial n}{\partial c}\right)_{t}=\frac{m_{1}}{m_{t}}\left(\frac{\partial n}{\partial c}\right)_{1}+\frac{m_{2}}{m_{t}}\left(\frac{\partial n}{\partial c}\right)_{2} \quad \text { and } \\
\left(\varepsilon_{\mathrm{abs}}\right)_{t}=\frac{m_{1}}{m_{t}}\left(\varepsilon_{\mathrm{abs}}\right)_{1}+\frac{m_{2}}{m_{t}}\left(\varepsilon_{\mathrm{abs}}\right)_{2}
\end{gathered}
$$

Knowing $\partial n / \partial c$ and $\varepsilon_{\text {abs }}$ for each component, these equations can be solved simultaneously to determine the mass fractions of each component of the conjugate. Valency information was obtained in this manner by dividing the total average ligand molar mass of the conjugate (mass protein or peptide per mole conjugate) by the individual ligand molecular weight.

Analysis of Hyaluronic Acid Conjugate Synthesis Products. Conjugates were made with $\mathrm{HyA}$ and Shh at several reaction ratios, and the products were characterized by SECMALS-RI-UV. Signals from the concentration detectors combined with MALS data were used to calculate the HyA and ligand molecular masses, as depicted in Figure 3 for HyAShh (1:40, HyA:Shh molar reaction ratio) conjugates made with 1.0 MDa HyA. These values for each conjugate were used to determine protein fraction distributions along the chromatograms, as presented in Figure 4. The quality of the data collected depended on the overall concentration of the conjugate as well as its degree of substitution. The cumulative and differential mass fractions were plotted against molar mass in Figure 5, depicting molecular weight distributions. The reaction and final ligand concentrations along with $\mathrm{HyA}$ and total ligand molecular weights of conjugate products are listed in Table 3 and Table 4.

The molecular weights of the HyA after Shh conjugation varied from batch to batch (Figure 6). It is known that HyA is 

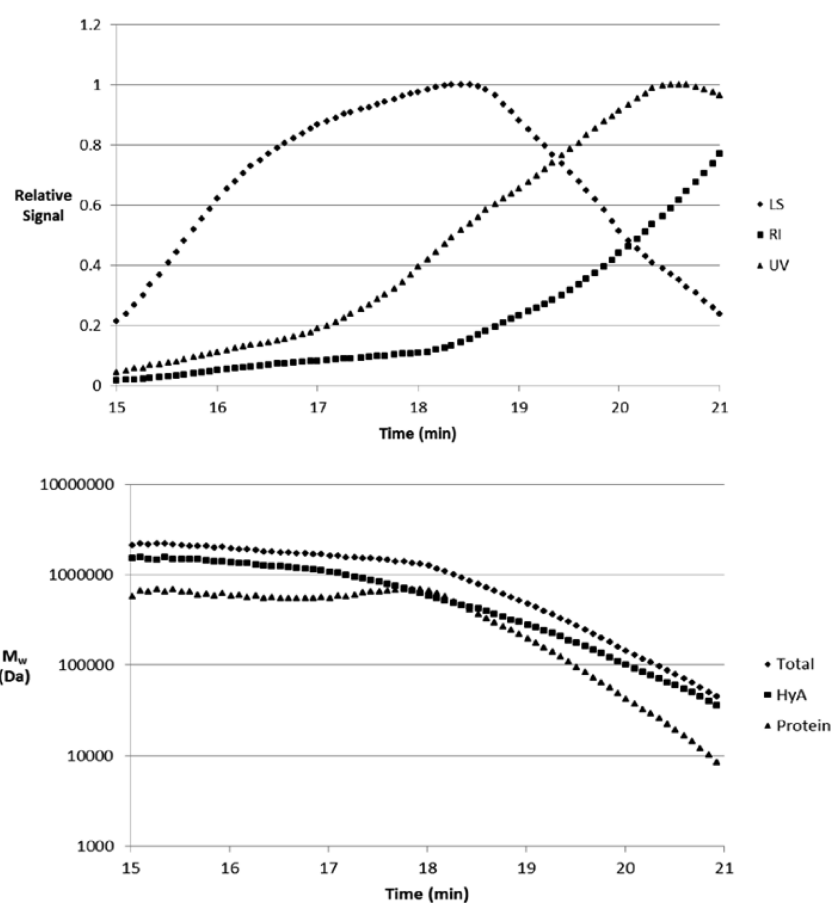

Figure 3. Detector signals $\left(90^{\circ}\right.$ light scattering, LS, refractive index, $\mathrm{RI}$, and ultraviolet light absorbance, UV) (a) collected during sizeexclusion chromatography (SEC) combined with MALS data allowed calculation of hyaluronic acid and protein molecular weight distributions (b) of the HyA-Shh (1:40, HyA:Shh molar reaction ratio) conjugate. susceptible to hydrolytic degradation, particularly under shear (e.g., in a stirred reaction, upon vortexing, or during sonication) or catalytic chemical conditions (e.g., acidic, alkaline, reductive, or oxidative). A reducing agent was used in the conjugation reaction, and the conjugate was exposed to shear in several steps of the reaction (stirring, pipetting). It is believed that the reducing conditions and shear led to molecular weight degradation of the HyA bioconjugates. The large variation in molecular weights is likely further due to differences in the way that the conjugates were handled, such as differences in stirring times or shear rates.

The input and output degrees of substitution (DS) for several HyA-Shh conjugates are plotted in Figure 7. Input and output DS were calculated according to

$$
\begin{aligned}
& \text { DS }=\frac{\# \text { ligands } / \text { molecule }}{\# \text { carboxylates } / \text { molecule }} \\
& \text { input DS }=\frac{\mathrm{mols}_{\text {ligand }}}{\frac{\mathrm{MW}_{\mathrm{w}_{\mathrm{HyA}}}}{\mathrm{MW}_{\mathrm{HyAdimer}}} \times \text { mols }_{\mathrm{HyA}}} \\
& \text { mols }_{\text {ligand }}=\frac{\text { mass }_{\text {ligand,input }}}{\mathrm{MW}_{\text {ligand }}} \\
& \text { mols }_{\mathrm{HyA}}=\frac{\text { mass }_{\mathrm{HyA}, \text { input }}}{\mathrm{MW}_{\mathrm{HyA}}^{*}} \\
& \text { output DS }=\frac{\mathrm{MW}_{\mathrm{w}_{\text {ligand }}}}{M W_{\text {ligand }}^{\prime}} \div \frac{\mathrm{MW}_{\mathrm{w}_{\mathrm{HyA}}}}{M W_{\text {HyAdimer }}}
\end{aligned}
$$
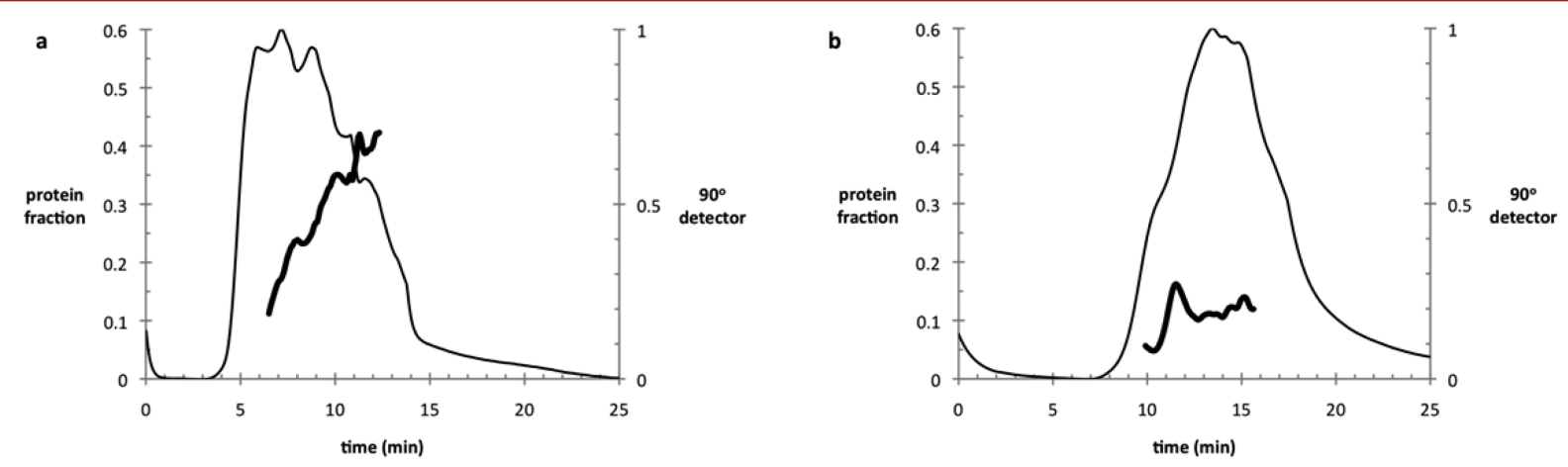

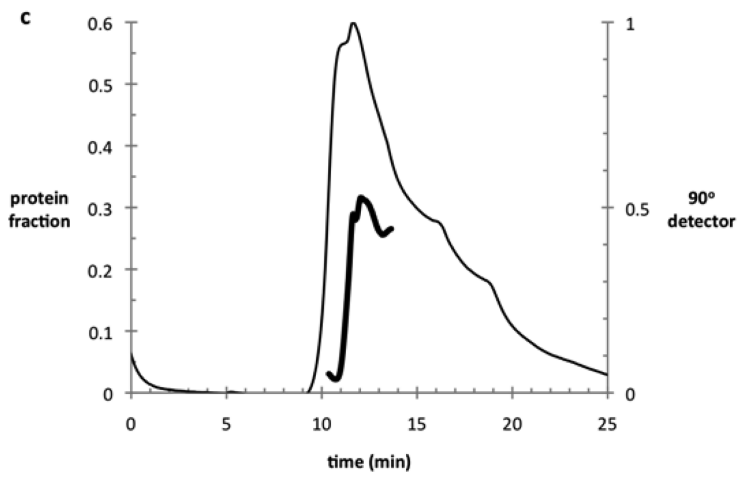

Figure 4. Protein fraction (dark line) and $90^{\circ}$ light scattering intensity (light line) of (a) HyA-bsp-RGD(15) (1:25), (b) HyA-Shh (1:20), and (c) HyA-Shh $(1: 40)$ following size-exclusion chromatography. Light scattering instensity depends on concentration and total molar mass, with higher molar masses eluted first. Conjugation of bsp-RGD was more efficient than Shh, with smaller input reaction ratios achieving a higher final protein fraction due to the small size and ease of accessibility to the bsp-RGD reaction site when compared to Shh. 

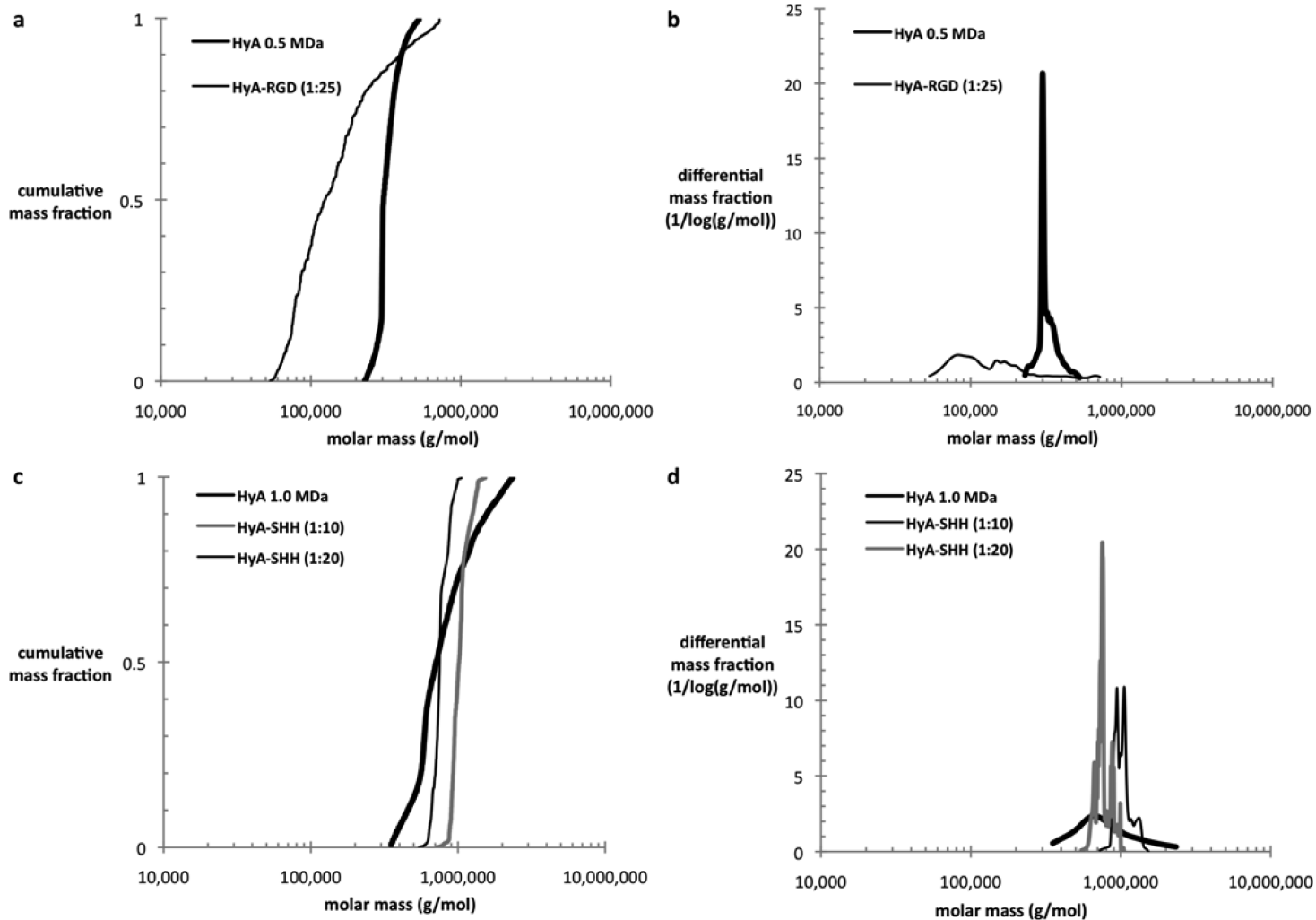

Figure 5. Cumulative $(a, c)$ and differential $(b, d)$ mass fractions versus molar mass of (a,b) 0.5 MDa HyA and HyA-bsp-RGD(15) (1:25) along with (c, d) 1.0 MDa HyA, HyA-Shh (1:20), and HyA-Shh (1:40).

Table 3. Bioconjugate Characterization of HyA-Peptide Products by SEC-MALS-RI-UV

\begin{tabular}{ccccccc} 
& $\begin{array}{c}\text { reaction } \\
\text { molar } \\
\text { ratio }\end{array}$ & $\begin{array}{c}\text { reaction } \\
\text { mass } \\
\text { fraction }\end{array}$ & $\begin{array}{c}\text { output } \\
\text { ligand } \\
\text { mass } \\
\text { fraction }\end{array}$ & $\begin{array}{c}\mathrm{MW}_{\mathrm{w}} \\
\mathrm{HyA}\end{array}$ & $\begin{array}{c}\mathrm{MW}_{\mathrm{w}} \\
\text { ligand } \\
(\mathrm{kDa})\end{array}$ & $\begin{array}{c}\text { conjugate } \\
\text { valency }\end{array}$ \\
$\begin{array}{c}\text { HyA, 0.5 } \\
\text { MDa }\end{array}$ & & & & 491 & & \\
$\begin{array}{c}\text { HyA- } \\
\text { bspRGD }\end{array}$ & 10 & 0.04 & 0.09 & 413 & 19 & 11.5 \\
$\begin{array}{c}\text { 1:10 } \\
\text { HyA- } \\
\text { bspRGD } \\
\mathbf{1 : 2 5}\end{array}$ & 25 & 0.11 & 0.33 & 141 & 72 & 43.4 \\
\hline
\end{tabular}

*based on nominal HyA MW.

In these equations, primed quantities refer to the molecular weight of a single peptide or protein molecule. $\mathrm{MW}_{\mathrm{w}}$ refers to the weight average molecular weight. Hyaluronic acid molecular weight was normalized by the dimer molecular weight as there is one reactive carboxylate group per dimer.

Differences in reaction efficiency between bsp-RGD(15) and Shh protein can be attributed to the higher molecular weight and steric hindrance of Shh protein. Higher conjugation
HyA Molecular Weight

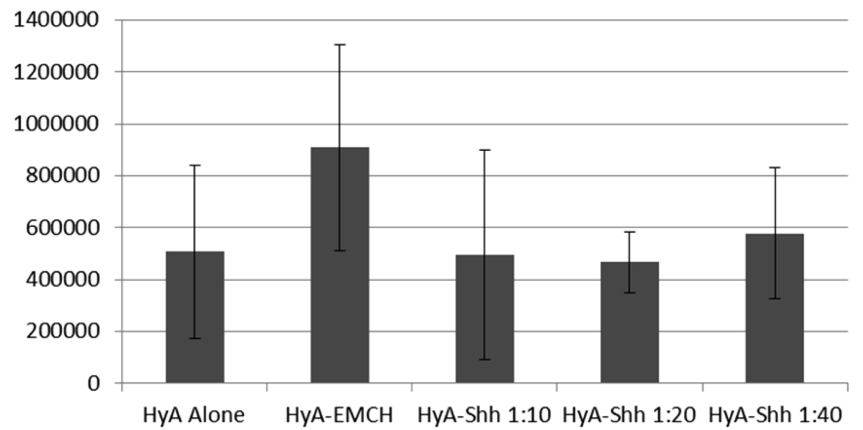

Figure 6. Weight-averaged molecular weights of hyaluronic acid in conjugates of varying reaction ratio. The error bars represent the standard deviation $(N=3)$.

efficiency of Shh to HyA was achieved when the reactions were performed at lower total reagent concentration (data not shown).

Comparison of SEC-MALS-RI-UV Results with Input Ratios and BCA Results. Protein fractions measured by SECMALS-RI-UV corresponded well with results determined by

Table 4. Bioconjugate Characterization of HyA-Shh Products by SEC-MALS-RI-UV

reaction molar ratio reaction mass fraction output ligand mass fraction $\mathrm{MW}_{\mathrm{w}} \mathrm{HyA}(\mathrm{kDa}) \quad \mathrm{MW}_{\mathrm{w}}$ ligand $(\mathrm{kDa}) \quad$ conjugate valency

HyA, 1.0 MDa

HyA-EMCH

HyA-Shh 1:10

HyA-Shh 1:20

HyA-Shh 1:40
20

40
0.22

0.43

0.87
$0.06 \pm 0.01$

$0.23 \pm 0.04$

$0.27 \pm 0.10$
$508 \pm 335$

$909 \pm 398$

$496 \pm 403$

$468 \pm 118$

$578 \pm 252$
0

0.0

$36 \pm 22$

$128 \pm 49$

$187 \pm 33$
$1.7+1.0$

$6.0 \pm 2.3$

$8.7 \pm 1.6$ 


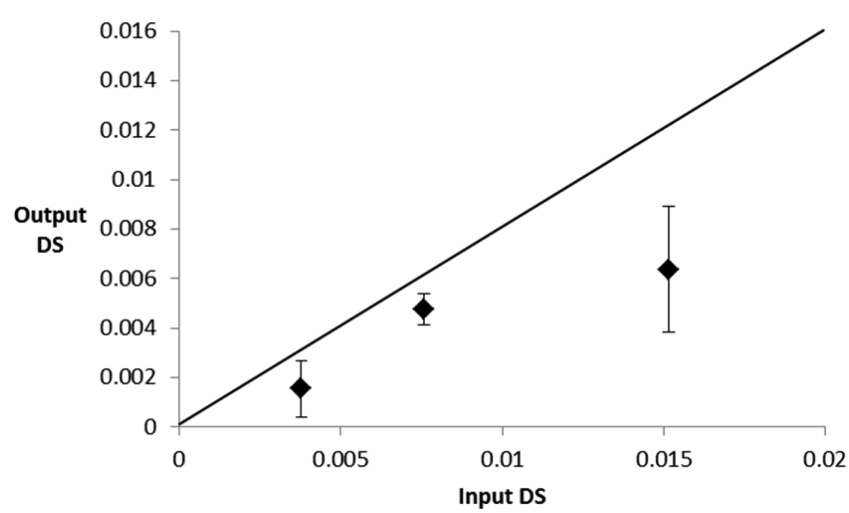

Figure 7. Input and output degrees of substitution (DS) values for HyA-Shh conjugates. The line represents correspondence of 1:1.

BCA protein measurements for a given batch of conjugate. The final conjugate valency differed from that calculated through the BCA assay, however (Figure 8). Differences in calculated

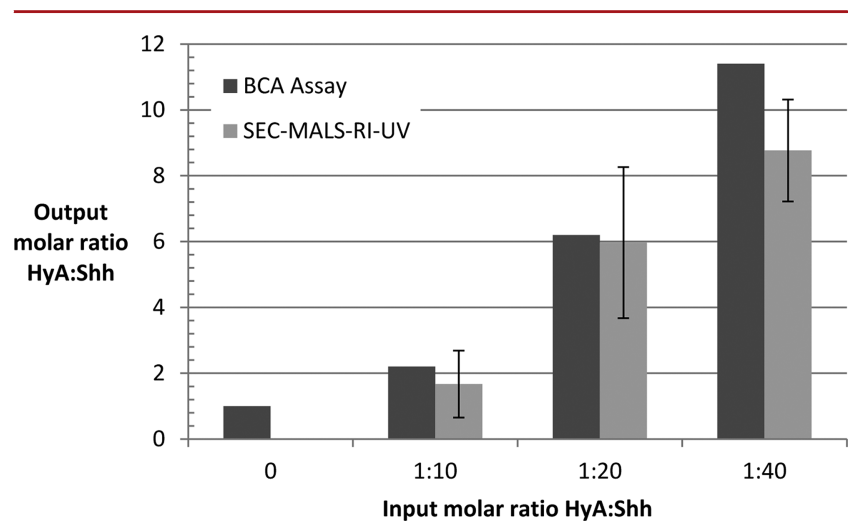

Figure 8. Comparison of input and output molar ratios as determined by SEC-MALS-RI-UV and BCA assay methods. Error bars represent the standard deviation $(N=3)$.

valency between SEC-MALS-RI-UV and BCA assay were due largely to fragmentation of the HyA backbone during the conjugate synthesis, and subsequently accounting for changes in the molecular weight. Valency determined by SEC-MALSRI-UV was calculated based on the total weight-averaged ligand molecular weight in each conjugate divided by the molecular weight of the individual ligand, whereas in the BCA assay determination, the mass ratio of ligand to HyA was used to calculate the molar ratio based on the ligand and original HyA molecular weights. Using the valency data collected from the BCA measurements leads to a misinterpretation of multivalent macromolecular values, whereas that calculated using the SECMALS-RI-UV does not.

\section{CONCLUSION}

SEC-MALS with RI and UV detection is valuable for determining the molecular weight and protein fraction distributions of polymer bioconjugates. The amount of material needed for this method depends upon instrument sensitivity, molecular weight, and reagent physiochemical parameters, but is significantly less than standard methods (i.e., BCA). Accurate measurement of protein fraction requires that the bioconjugate components have differing refractive index increments and UV absorbance coefficients. These values can be determined using online or offline analysis of unconjugated reagents. SEC-MALS with triple detection (MALS, RI, UV) can also be used to accurately measure bioconjugation reaction efficiency and provide detailed molecular structural information along with precise distribution of substitution and valency data. In contrast, with the large variation in actual HyA molecular weight after the conjugation reaction, accurate measurement of the valency of the bioconjugates is impossible using more conventional batch techniques such as a BCA assay. Moreover, the capabilities of this method could be expanded by using the diode array detector (DAD) on a high-performance liquid chromatography (HPLC) instrument to measure UV absorbance at multiple wavelengths in order to simultaneously identify conjugate components with different absorbance spectra. In either case, more accurate deduction of the molecular structures of polymer bioconjugates can be used to improve macromolecular engineering design principles and better understand multivalent macromolecular interactions (e.g., receptor-ligand dynamics and enzyme kinetics). Furthermore, this analysis method can be used for quality assurance and to optimize reactor design and operations for large-scale production of designer bioconjugate products.

\section{AUTHOR INFORMATION}

\section{Corresponding Author}

*Fax: 510 642-5835. Tel: 510 642-3559. E-mail: kehealy@ berkeley.edu.

\section{Notes}

The authors declare no competing financial interest.

\section{ACKNOWLEDGMENTS}

This work was supported in part by the American Heart Association \#20082098, National Science Foundation (NSF Graduate Fellowship to JFP), the University of California at Berkeley (Berkeley Graduate Fellowship to JFP), the California Institute for Regenerative Medicine (Postdoctoral Fellowship to RSA), NIH R21EB007295, NIH NHLBI R01HL096525. The authors thank Melissa Velasquez for her assistance in HyApeptide synthesis.

\section{REFERENCES}

(1) Elbert, D., and Hubbell, J. (2001) Conjugate addition reactions combined with free-radical cross-linking for the design of materials for tissue engineering. Biomacromolecules 2, 430-441.

(2) Wall, S. T., Saha, K., Ashton, R. S., Kam, K. R., Schaffer, D. V., and Healy, K. E. (2008) Multivalency of Sonic hedgehog conjugated to linear polymer chains modulates protein potency. Bioconjugate Chem. $19,806-12$.

(3) Drumheller, P., Elbert, D., and Hubbell, J. (1994) Multifunctional poly (ethylene glycol) semi-interpenetrating polymer networks as highly selective adhesive substrates for bioadhesive peptide grafting. Biotechnol. Bioeng. 43, 772-780.

(4) Stile, R. A., and Healy, K. E. (2001) Thermo-responsive peptidemodified hydrogels for tissue regeneration. Biomacromolecules 2, 18594.

(5) Ho, M., Wang, D., Hsieh, H., Liu, H., Hsien, T., Lai, J., and Hou, L. (2005) Preparation and characterization of RGD-immobilized chitosan scaffolds. Biomaterials 26, 3197-3206.

(6) Ito, Y. (2008) Covalently immobilized biosignal molecule materials for tissue engineering. Soft Matter 4, 46-56.

(7) Sacchettini, J. C., Baum, L. G., and Brewer, C. F. (2001) Multivalent protein-carbohydrate interactions. A new paradigm for supermolecular assembly and signal transduction. Biochemistry 40, 3009-15. 
(8) Kiessling, L. L., Gestwicki, J. E., and Strong, L. E. (2000) Synthetic multivalent ligands in the exploration of cell-surface interactions. Curr. Opin. Chem. Biol. 4, 696-703.

(9) Schamel, W. W. A., and Reth, M. (2008) Clustering models. Adv. Exp. Med. Biol. 640, 64-73.

(10) Geiger, B., Bershadsky, A., Pankov, R., and Yamada, K. M. (2001) Transmembrane crosstalk between the extracellular matrixcytoskeleton crosstalk. Nat. Rev. Mol. Cell Biol. 2, 793-805.

(11) Huveneers, S., and Danen, E. H. J. (2009) Adhesion signaling crosstalk between integrins, Src and Rho. J. Cell Sci. 122, 1059-69.

(12) McLellan, J. S., Zheng, X., Hauk, G., Ghirlando, R., Beachy, P. A., and Leahy, D. J. (2008) The mode of Hedgehog binding to Ihog homologues is not conserved across different phyla. Nature 455, 97983.

(13) Saha, K., Pollock, J. F., Schaffer, D. V., and Healy, K. E. (2007) Designing synthetic materials to control stem cell phenotype. Curr. Opin. Chem. Biol. 11, 381-7.

(14) Bi, X., Shi, X., and Baker, J. R. (2008) Synthesis, characterization and stability of a luteinizing hormone-releasing hormone (LHRH)functionalized poly(amidoamine) dendrimer conjugate. J. Biomater. Sci., Polym. Ed. 19, 131-42.

(15) Wang, L., Amphlett, G., Blättler, W. A., Lambert, J. M., and Zhang, W. (2005) Structural characterization of the maytansinoidmonoclonal antibody immunoconjugate, huN901-DM1, by mass spectrometry. Protein Sci. 14, 2436-46.

(16) Cheng, W., Satyanarayanajois, S., and Lim, L.-Y. (2007) Aqueous-soluble, non-reversible lipid conjugate of salmon calcitonin: synthesis, characterization and in vivo activity. Pharm. Res. 24, 99-110.

(17) Tzokova, N., Fernyhough, C. M., Butler, M. F., Armes, S. P., Ryan, A. J., Topham, P. D., and Adams, D. J. (2009) The effect of PEO length on the self-assembly of poly(ethylene oxide)-tetrapeptide conjugates prepared by "Click" chemistry. Langmuir 25, 11082-9.

(18) Mi, F.-L. (2005) Synthesis and characterization of a novel chitosan-gelatin bioconjugate with fluorescence emission. Biomacromolecules 6, 975-87.

(19) Demolliens, A., Boucher, C., Durocher, Y., Jolicoeur, M., Buschmann, M. D., and De Crescenzo, G. (2008) Tyrosinase-catalyzed synthesis of a universal coil-chitosan bioconjugate for protein immobilization. Bioconjugate Chem. 19, 1849-54.

(20) Oh, E. J., Park, K., Choi, J.-S., Joo, C.-K., and Hahn, S. K. (2009) Synthesis, characterization, and preliminary assessment of anti-Flt 1 peptide-hyaluronate conjugate for the treatment of corneal neovascularization. Biomaterials 30, 6026-34.

(21) Wyatt, P. (1993) Light scattering and the absolute characterization of macromolecules. Anal. Chim. Acta,.

(22) Wen, J., Arakawa, T., and Philo, J. S. (1996) Size-exclusion chromatography with on-line light-scattering, absorbance, and refractive index detectors for studying proteins and their interactions. Anal. Biochem. 240, 155-66.

(23) Kendrick, B. S., Kerwin, B. A., Chang, B. S., and Philo, J. S. (2001) Online size-exclusion high-performance liquid chromatography light scattering and differential refractometry methods to determine degree of polymer conjugation to proteins and protein-protein or protein-ligand association states. Anal. Biochem. 299, 136-146.

(24) Ghosh, K., Shu, X. Z., Mou, R., Lombardi, J., Prestwich, G. D., Rafailovich, M. H., and Clark, R. A. (2005) Rheological characterization of in situ cross-linkable hyaluronan hydrogels. Biomacromolecules 6, 2857-65.

(25) Leach, J. B., Bivens, K. A., Collins, C. N., and Schmidt, C. E. (2004) Development of photocrosslinkable hyaluronic acid-polyethylene glycol-peptide composite hydrogels for soft tissue engineering. J. Biomed. Mater. Res., Part A 70, 74-82.

(26) Pouyani, T., and Prestwich, G. D. (1994) Functionalized derivatives of hyaluronic acid oligosaccharides: drug carriers and novel biomaterials. Bioconjugate Chem. 5, 339-47.

(27) Park, Y. D., Tirelli, N., and Hubbell, J. A. (2003) Photopolymerized hyaluronic acid-based hydrogels and interpenetrating networks. Biomaterials 24, 893-900.
(28) Peattie, R. A., Nayate, A. P., Firpo, M. A., Shelby, J., Fisher, R. J., and Prestwich, G. D. (2004) Stimulation of in vivo angiogenesis by cytokine-loaded hyaluronic acid hydrogel implants. Biomaterials 25 , 2789-98.

(29) Rezania, A., and Healy, K. (2000) The effect of peptide surface density on mineralization of a matrix deposited by osteogenic cells. $J$. Biomed. Mater. Res. 52, 595-600.

(30) Nomizu, M., Kim, W., Yamamura, K., Utani, A., Song, S., Otaka, A., Roller, P., Kleinman, H., and Yamada, Y. (1995) Identification of cell binding sites in the laminin alphal chain carboxyl-terminal globular domain by systematic screening of synthetic peptides. J. Biol. Chem. 270, 20583-90.

(31) Ho, J., Chung, E., Wall, S., Schaffer, D., and Healy, K. (2007) J. Biomed. Mater. Res., Part A 83, 1200-1208. 